\title{
EURORDIS Summer School for patient advocates in clinical trials and drug development
}

\author{
Maria Mavris, Fabrizia Bignami \\ From 5th European Conference on Rare Diseases (ECRD 2010) \\ Krakow, Poland. 13-15 May 2010
}

EURORDIS, the European Organisation for Rare Diseases launched this new initiative in 2008 with the support of the Drug Information Association (DIA) Philanthropy programme, the Association Française contre les Myopathies (AFM), Fundacio Dr. Robert and the European Agency for Health and Consumers (EAHC). Many of EURORDIS' members are extensively involved in EU decision-making processes in the European Medicines Agency (EMA), including as experts, patients' representatives and/or members of scientific committees and working parties.

The aim of the EURORDIS Summer School is to assist these and future patient advocates to i) better promote drug development, ii) be involved in regulatory affairs, and to iii) guarantee access to treatments and iv) improve the quality of orphan drug information to patients.

The 4-day programme consists of:

1) a description of the drug development process from clinical trials to regulatory stages and includes statistics, ethics and post-marketing aspects.

2) a description of the committees and working parties at the EMA with particular emphasis on the role of patients' representatives and

3) the role of EURORDIS and in particular of its "Task Forces" whose volunteers can also be involved in the above activities.

The aim of the Summer School is to:

1. to establish a forum for exchange of information, education and training for these high-level

*Correspondence: maria.mavris@eurordis.org

Eurordis, Plateforme Maladies Rares, 96 rue Didot, 75014 Paris, France selected patient advocates from a wide range of rare diseases across Europe;

2. to enhance the experience they have gained and their leadership capacities.

As patient advocates are increasingly involved in all aspects of drug development (from research to economic aspects), there is a growing need to provide support and training in these areas. The EURORDIS Summer School not only addresses these needs but also provides the means for advocates to interact with each other as well as with regulators, academic partners and industry. In addition to the learning experience, the Summer School provides an excellent forum for indepth exchange of information and experiences, all in the beautiful city of Barcelona.

Published: 19 October 2010

doi:10.1186/1750-1172-5-S1-P3

Cite this article as: Mavris and Bignami: EURORDIS Summer School for patient advocates in clinical trials and drug development. Orphanet Journal of Rare Diseases 2010 5(Suppl 1):P3.

Submit your next manuscript to BioMed Central and take full advantage of:

- Convenient online submission

- Thorough peer review

- No space constraints or color figure charges

- Immediate publication on acceptance

- Inclusion in PubIMed, CAS, Scopus and Google Scholar

- Research which is freely available for redistribution

Submit your manuscript at www biomedcentral.com/submit 